\title{
ARISTÓTELES Y ZUBIRI: VERDAD ANTEPREDICATIVA Y VERDAD REAL*
}

\author{
ARISTOTLE AND ZUBIRI: PRE-PREDICATIVE TRUTH \\ AND REAL TRUTH
}

\author{
JESÚS MANUEL CONDERANA CERRILlO \\ Universidad Pontificia de Salamanca
}

Recibido: 20/05/2019 Aceptado: 23/09/2019

\section{RESUMEN}

Nuestro trabajo describe las semejanzas y las diferencias entre la doctrina de Aristóteles y de Zubiri respecto a la concepción de la verdad. Aunque Zubiri insiste en señalar muy explícitamente sus discrepancias con las tesis aristotélicas, no es menos cierto que no difieren tan drásticamente en tesis centrales referidas a la concepción de la verdad. Coinciden en que es preciso que exista una verdad más radical y fundamental para que pueda hablarse de "verdad" y de "error" en sentido propio. Aristóteles llama a esa verdad fundamental "verdad antepredicativa", Zubiri la identifica con la "verdad real".

Palabras clave: Aristóteles; Zubiri; verdad antepredicativa; verdad real; epistemología.

\footnotetext{
* Resultado del Proyecto de Investigación de la Junta de Castilla y León: "La finalidad de los bienes: riqueza, pobreza y mendicidad en la polémica intelectual del s. XVI. Estudio y edición de fuentes de la Escuela de Salamanca" (PON227P18), años 2019-2021.
} 


\section{ABSTRACT}

Our work describes the similarities and differences between the doctrines of Aristotle and Zubiri regarding the concept of truth. Although Zubiri insists on highlighting very explicitly his discrepancies with the Aristotelian theses, they do not differ so drastically in the central theses which refer to the concept of truth. They agree that there must be a more radical and fundamental truth so that we can speak of "truth" and "error" in the proper sense. Aristotle names that fundamental truth "pre-predicative truth", whereas Zubiri identifies it with the "real truth".

Keywords: Aristotle, Zubiri, pre-predicative truth, real truth, epistemology.

\section{INTRODUCCIÓN}

Nuestra contribución pretende sacar a la luz algunas semejanzas y discrepancias que existen entre la doctrina aristotélica y zubiriana respecto a la concepción de la verdad. Aunque es cierto que Zubiri intenta apartarse de las tesis aristotélicas ${ }^{1}$ señalando claramente los puntos discordantes, no es menos cierto que es posible indicar también algunas tesis absolutamente fundamentales, como veremos, en que la inspiración en Aristóteles nos parece manifiesta. Esto es precisamente lo que intentaremos mostrar con este trabajo. El planteamiento más básico y común a ambos es entender que para que exista verdad y error en sentido estricto y habitual es preciso suponer otro tipo de verdad más radical y fundamental que es su punto arquimédico. En Aristóteles dicha verdad puede denominarse "verdad antepredicativa"2, Zubiri la llama "verdad real".

El esquema de nuestro trabajo será el siguiente: después de estudiar por separado las doctrinas de ambos autores terminaremos comparándolas para

1 Para darse cuenta de ello basta echar una ojeada a la voz "Aristóteles", por ejemplo, en los índices de Xavier Zubiri, Sobre la esencia, 4.a ed. (Madrid: Sociedad de Estudios y Publicaciones, 1962), Xavier Zubiri, El hombre y la verdad (Madrid: Alianza Editorial, 1999) y de Xavier Zubiri, Inteligencia sentiente. *Inteligencia y realidad (Madrid: Alianza Editorial, 1980). La mayor parte de las referencias son críticas. Raramente Zubiri reseña un débito respecto del de Estagira. Desde nuestro punto de vista, el tema clave de la verdad real que analizamos es una de esas deudas no confesadas por Zubiri.

2 Tomamos esta expresión de Joseph Moreau, "Aristote et la vérité antépredicative", en Aristote et les problémes de méthode (Communications présentées au Symposium Aristotelicum tenu à Louvain du 24 août au ler septembre 1960), ed. Suzanne Mansion (Louvain-Paris: Publications Universitaires de Louvain-Éditions Béatrice-Neuwelaerts, 1980), 21-33. 
hacer ver tanto las discrepancias como, a nuestro modo de ver, las profundas similitudes entre ambos planteamientos.

\section{LA CONCEPCIÓN DE LA VERDAD EN ARISTÓTELES}

Hemos de señalar que la interpretación de Aristóteles que vamos a exponer no está exenta de dificultades interpretativas. No es nuestro objetivo en este escrito polemizar con versiones rivales. Simplemente trataremos de sostener nuestra interpretación con argumentos tomados lo más explícitamente posible de los textos. Por este motivo incluimos en nuestro escrito, debidamente contextualizados, los textos aristotélicos claves para el problema que examinamos.

Los textos fundamentales donde Aristóteles define explícitamente su concepción de la verdad son De interpretatione $e^{3}$ y Metaphysica ${ }^{4}$. En ellos la tesis básica normalmente admitida por los intérpretes señala que la verdad en sentido estricto consiste en una conformidad entre el intelecto y la realidad ${ }^{5}$. Pero hay que entender bien esta conformidad, pues la verdad solo se encuentra en el juicio que relaciona dos términos "uniéndolos" o "separándolos". La verdad y la fal-

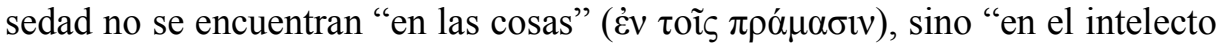
discursivo" ( $\dot{\varepsilon} v \delta 1 \alpha v o i ́ \alpha)$ que es el que tiene la capacidad de "unir" o "separar"7.

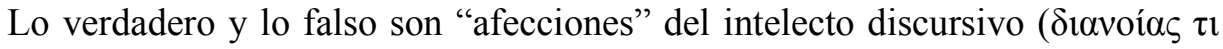

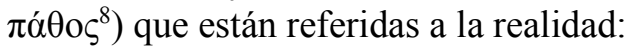

"Desde luego, tú no eres blanco porque sea verdadero nuestro juicio de que tú eres blanco, sino, al contrario, porque tú eres blanco, nosotros decimos algo verdadero al afirmarlo"'.

3 De inter. 1, 16a 9-18. Empleamos: Aristóteles, Tratados de lógica (Órganon) II: Sobre la interpretación, Analíticos primeros, Analíticos segundos, ed. Miguel Candel Sanmartín (Madrid: Gredos, 1988).

$4 \quad$ Metaph. IV, 4, 1027b 17-28; IX, 10, 1051a 34-b 9.

5 En Xavier Zubiri, El hombre y la verdad, 20, Zubiri señala que dicha tesis no se encuentra literalmente en Aristóteles. En la misma página hay una alusión de Zubiri a los textos donde se puede leer en Aristóteles lo que hemos llamado aquí "verdad antepredicativa".

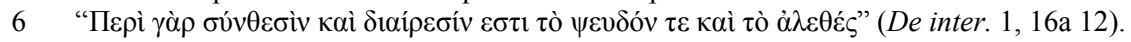

7 Santo Tomás recoge esta doctrina diciendo que la verdad se encuentra in intellectu componente et dividente (ST I, 16, 2c). Empleamos Sancti Thomae Aquinatis, Summa Theologiae (texto latino de la edición crítica Leonina y traducción castellana) (Madrid: Biblioteca de Autores Cristianos, 1954). Sobre el origen platónico de esta doctrina véase Moreau, "Aristote et la vérité antépredicative", 21-22.

8 Metaph. VI, 4, 1028a 1.

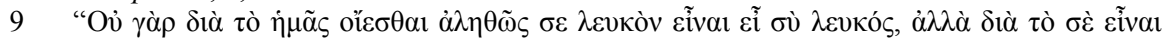

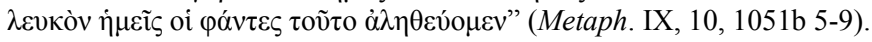


El texto que acabamos de citar plantea la cuestión tradicional de la existencia de una verdad ontológica como fundamento de una verdad lógica (del intelecto discursivo, como venimos diciendo). Existe apoyo textual para sostener que esta distinción puede encontrarse en Aristóteles en las páginas de la $\mathrm{Me}$ taphysica que estamos comentando. Justamente al inicio del capítulo dice Aristóteles:

"Puesto que 'lo que es' y 'lo que no es' se dicen, en un sentido según las figuras de la predicación, en otro sentido según la potencia y el acto de éstas, o sus contrarios, y en otro sentido, lo que es verdadero o es falso en el sentido más fundamental, lo cual tiene lugar en las cosas según estén unidas o separadas, de modo que dice la verdad el que juzga que lo separado está separado y que lo unido está unido, y dice falsedad aquel cuyo juicio está articulado al contrario de las cosas $[\ldots]^{\prime \prime 10}$.

Según el texto hay un sentido fundamental ${ }^{11}$ para verdadero y falso que tiene lugar en la realidad: consiste en los estados de cosas del mundo. Esta verdad ontológica (cómo están las cosas en la realidad) es el fundamento de la verdad lógica (quien dice cómo están las cosas predicando relaciones de unas con respecto a otras).

Ahora bien, para que la verdad en sentido estricto, que es la verdad del juicio, pueda existir, para que sea posible verificar la adecuación de las relaciones establecidas en el juicio con la realidad, es preciso que la verdad ontológica nos sea dada de una manera que no precise de verificación alguna, en caso contrario caeríamos en un regreso al infinito de verificación de verificaciones. Es claro, pues, que esta concepción predicativa de la verdad necesita de una verdad anterior a la predicación y que, por ello, podemos llamar "verdad antepredicativa". Esta verdad antepredicativa no puede conceptuarse como "conformidad" puesto que ella se presenta como fundamento de dicha conformidad, como criterio desde el que poder discernir la conformidad misma.

Pero ¿a qué nos referimos cuando hablamos de "verdad antepredicativa"? Nos referimos al modo en que se captan, según Aristóteles, ciertos tipos de

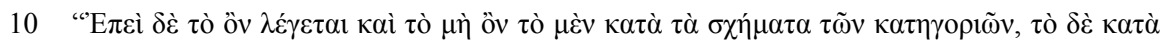

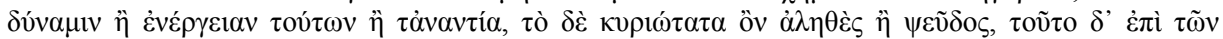

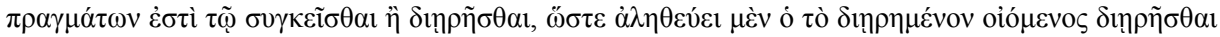

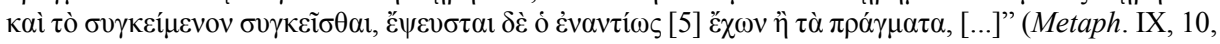
1051a 34-b 5).

11 Como muestra muy bien Tomás Calvo (Aristóteles, Metafisica, ed. Tomás Calvo Martínez (Madrid: Gredos, 1994), 389-90, nota 45) no es preciso suprimir nada del texto, pues es perfectamente comprensible y coherente, contrariamente a lo que supone Ross: Aristotle, Metaphysics, ed. W. David Ross (Oxford: Clarendon Press, 1924). 
sensibles y los indivisibles o realidades carentes de composición. Estaríamos delante de lo que De interpretatione denomina un pensamiento sin composición ni separación ${ }^{12}$. Serán estos elementos los que luego entrarán en composición o separación en las proposiciones dando lugar a la verdad y falsedad en sentido estricto. Estudiamos a continuación estos dos grupos de elementos.

\section{EL CONOCIMIENTO DE LO SENSIBLE}

La teoría de la percepción del Filósofo distingue tres tipos de sensibles:

(a) Sensibles propios ('i $\delta 1 \alpha \alpha i \sigma \theta \varepsilon \tau \alpha ́$ ). Son el objeto característico de cada sentido: el color para el ojo, el sonido para el oído, el olor para el olfato, el sabor para el gusto y las cualidades táctiles para el tacto. Este objeto está definido por pares de opuestos ${ }^{13}$.

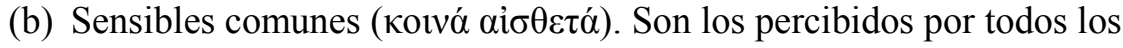
sentidos o por varios, especialmente por la vista y el tacto. Se trata de la forma, el movimiento, el reposo, el número y el tamaño ${ }^{14}$. La percepción de un triángulo en matemáticas es la percepción de un sensible común. En efecto, a la forma se accede mediante la vista o el tacto.

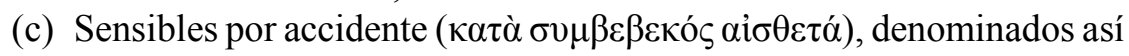
en oposición a los dos anteriores que son sensibles por sí mismos

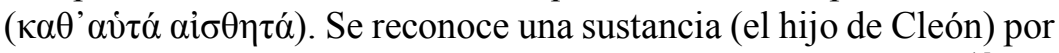
la percepción de sus cualidades accidentales (el color blanco ${ }^{15}$. La diferencia específica entre la percepción de los sensibles por accidente y la percepción de los sensibles propios es que en la primera hay predicación de atributos, mientras que en la segunda no existe propiamente predicación y por eso tampoco cabe el error. En la percepción incidental se afirma que "eso blanco que se acerca es el hijo de Cleón". En esta identificación sí puede existir verdad y error en sentido propio.

12 Cf. De inter. 1, 16 a 14.

13 En el caso del tacto no resulta tan claro (cf. Deborah K. W Modrak, Aristotle. The Power of Perception (Chicago-London: University of Chicago Press, 1987), 41).

14 De an. II, 6, 418a 17-20; 425a 14-16: Aristóteles, Acerca del alma, ed. Tomás Calvo Martínez (Madrid: Gredos, 1988). De somn. 1, 458b 4-6: Aristotle, Parva naturalia, ed. W. David Ross (Oxford: Oxford University Press, 1970).

15 En la percepción incidental se toma la sustancia (hijo de Cleón), primera en el orden ontológico, como un atributo de lo que en el orden real es un accidente (blanco). La sustancia se conoce como atributo de algo percibido necesariamente: un sensible propio: cf. Antonio Bravo García, "Fisiología y filosofía en Aristóteles: el problema de los sueños", Cuadernos de Filología (C. Univ. de Ciudad Real) 4 (1985): 39-40. 
Los sensibles comunes comparten con los propios el ser percibidos directamente; con los sensibles por accidente, implicar un cierto juicio. Son percibidos directamente por dos o más sentidos y en esa percepción se da una cierta unión o separación que puede dar paso al error: no se percibe "una forma", sino "un cierto color con cierta forma" ${ }^{16}$, por ejemplo.

Hablar de "error" en el caso de los sensibles propios implica usar el término en sentido traslaticio (como "ocasión de error"), puesto que, según Aristóteles, el error propiamente dicho sólo puede darse cuando existe unión o separación de noemas ${ }^{17}$. En la aprehensión de los sensibles propios se da una operación simple que acaba en un objeto simple. Puesto que la operación afirmativa se identifica con el objeto afirmado, no hay, por así decir, una distancia entre ellos que permita el error. La causa de la infalibilidad, también para los indivisibles, está en que se trata de unidades que han de ser simplemente descubiertas. Por este motivo aquellas unidades que el intelecto no se encuentra, sino que produce (síntesis, atribución, predicación) pueden ser susceptibles de verdad y error en sentido estricto.

En la aprehensión inmediata de los sensibles propios y, en cierta medida, en la aprehensión de los sensibles comunes, se puede hablar de verdad antepredicativa, pues es una verdad conocida infaliblemente que es fundamento de la verdad de la predicación. Es esta aprehensión inmediata la que entra a formar parte de los juicios en que se da ya composición y división y, por tanto, en que se da la presencia de la verdad o falsedad en sentido estricto.

\section{LA INTELECCIÓN DE LOS INDIVISIBLES}

El segundo grupo de elementos que nos proponemos estudiar es bastante más complejo que el anterior. Partiremos de la interpretación de dos textos básicos donde Aristóteles estudia con un cierto detalle los tipos de indivisibles y el modo en que son conocidos.

\subsection{De an. $I I I, 6$}

Presentamos a continuación el contenido de este texto de no fácil lectura. De an. III, 6 distingue dos funciones del intelecto: la intelección de los indivisibles y la síntesis de nociones producida por otro tipo de intelección. Se dice que la primera está libre de errores, mientras que la segunda es susceptible de errar

16 Cf. Stefano Besoli, "Percezione, verità e giudizio: Luoghi dell'intuizionismo aristotelico", Annali dell'Instituto discipline filosofiche dell'Università di Bologna 4 (1982): 16-17.

17 Cf. De an. II, 6, 418a 12-16; III, 3, 427b 12; 428a 11; b 18-25; De sensu 4, 442b 8-10; Metaph. IV, 5, 1010b 2; IX, 10. 
(430a 26-28), pues el error solo puede tener lugar donde hay composición producida por el intelecto (430b 2).

Se dice, además, que existen dos tipos de indivisibles: aquellos que son potencialmente indivisibles, es decir, aquellos que no es posible dividirlos de ningún modo y aquellos que son indivisibles actualmente, es decir que de hecho no están divididos, pero que son divisibles en potencia (430b 6-9).

Es interesante notar que se hace mención del tiempo en relación a la intelección en general y a la de los indivisibles en particular. La intelección del indivisible se realiza en un tiempo indivisible. Se entiende que un tiempo indivisible es aquel que no supone sucesión ${ }^{18}$.

Aristóteles no ofrece en la primera parte del texto ejemplos de este tipo de unidades que el intelecto encuentra, pero sí de unidades producidas por el intelecto por composición: "la diagonal es inconmensurable" y "Cleón es blanco". Son ejemplos tomados de las matemáticas y de la física.

Aristóteles propone una serie de categorías de indivisibles.

a) Indivisibles según la cantidad. Así, por ejemplo, la longitud, entendida como indivisible en acto, aunque potencialmente sea divisible.

b) Indivisibles según la forma específica. Aristóteles no da ningún ejemplo de este segundo tipo en esta parte del texto. Señala, sin embargo, que se intelige en un tiempo indivisible y por un acto indivisible del alma.

c) Indivisibles que actúan como elementos divisorios o límites. Así, por ejemplo, el punto ${ }^{19}$. Su intelección se realiza del mismo modo que la de los siguientes indivisibles ${ }^{20}$.

d) Indivisibles según la privación. Así, por ejemplo, lo malo o lo negro. De algún modo se conocen por su contrario, entendiendo aquí por contrario, la realidad que existe por sí: el bien o lo blanco (el mal es ausencia del bien y lo negro, ausencia de blanco).

18 De la importante cuestión del tiempo en referencia al conocimiento de los indivisibles nos ocupamos más adelante.

19 Se entiende que el punto es elemento límite de la línea: la línea en el límite es un punto. Como elemento divisorio, el punto señala el límite entre dos líneas. Del mismo modo, la línea es límite o elemento divisorio del plano y éste lo es de la figura tridimensional.

20 No se entiende muy bien en qué sentido el modo de conocimiento ha de ser el mismo. Podría serlo si privación y límite fueran realidades de la misma naturaleza. 
e) Indivisibles que carecen de contrario. Se trata de realidades que existen en acto y separadas. Los intérpretes las identifican con las inteligencias divinas o los motores inmóviles. Serían realidades indivisibles en acto que no pueden dividirse ni siquiera en potencia. El texto parece referirse también al dios aristotélico ${ }^{21}$.

El texto aristotélico termina con dos precisiones. En primer lugar señala que cuando se intelige "qué es algo en cuanto a su esencia", esta intelección es siempre verdadera, pues no predica nada de ningún sujeto. Sucede algo parecido a lo que ocurre cuando se trata de los sensibles propios para cada sentido: es imposible el error. En segundo lugar, el texto señala que esto mismo sucede respecto de la intelección de los objetos separados de la materia. Por lo que diremos más adelante, suponemos que estos objetos son las esencias inmateriales de realidades materiales.

\subsection{Metaph. $I X, 10$ y su relación con De an. III, 6}

El texto que acabamos de resumir parece estar en estrecha congruencia con Metaph. IX, 10. En este texto, Aristóteles, tras recordar los distintos sentidos de "ser" y de "lo que es", se ocupa de la existencia de la verdad y la falsedad relativas a las realidades compuestas. A continuación analiza el sentido de verdad referido en primer lugar a "cosas carentes de composición" y después el referido a "entidades carentes de composición".

Cosas carentes de composición. Aristóteles no propone directamente ningún ejemplo, pero, dado que se trata de "cosas carentes de composición" puede suponerse que se tratará de realidades que entran en la "composición" en las proposiciones donde sí se da la verdad en sentido estricto. Si hemos supuesto bien, entonces tendremos ejemplos del tipo "madera", "blanco", "inconmensurable" y "diagonal" que son las realidades que entran en composiciones del tipo "la madera es blanca" o "la diagonal es inconmensurable". Se trata, por tanto, del tipo de realidades físicas y matemáticas que ya encontramos en el texto del De anima ${ }^{22}$. Las "cosas carentes de composición" coinciden con algunos de los indivisibles del De anima. La diferencia de términos apunta a matices interesantes: en el De

21 Cf. Jannone-Barbotin (Aristote, De l'âme (Paris: Les Belles Lettres, 1996), 108, nota 1 de página 84) señalan que lo Primero no tiene contrario alguno (Metaph. XII, 10, 1075 b 20).

22 No podemos pensar que serán indivisibles todos los elementos que aparecen en las proposiciones ("composiciones"), una vez que los tomemos aislados de ellas. Así, en el ejemplo "Cleón es blanco" (De an. III, 6, 430b 5), ciertamente blanco es un sensible propio, pero Cleón no es un indivisible: no entra en ninguno de los tipos de indivisibles propuestos por Aristóteles a continuación de este ejemplo (De an. III, 6, 430b 6-26). 
anima se subraya la universalidad y la unidad; Metaphysica señala su separabilidad, condición para ser captado directamente por el intelecto. Se trata, pues, de universales considerados en y por sí mismos sin conexión con otros, que se conocen por sí mismos en lo que cada uno es.

¿A qué se puede referir Aristóteles con entidades carentes de composición? De ellas Aristóteles enuncia varias características: se dan siempre en acto, nunca en potencia, no se generan ni se destruyen, son siempre "lo que es mismo" (

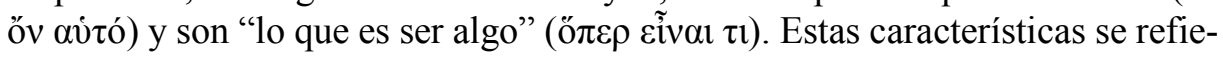
ren claramente a las esencias de sustancias materiales, es decir a esencias inmateriales de sustancias materiales: las formas sustanciales. También ellas están presentes en el texto del De anima: son los “objetos separados de la materia" del final del texto.

También el texto de Metaphysica, del mismo modo que el de De anima, señala que acerca de estas realidades:

"La verdad y la falsedad consisten en esto: la verdad, en captar y enunciar la cosa (pues enunciar y afirmar no son lo mismo), mientras que ignorarla consiste en no captarla ya que no cabe el error acerca del qué, a no ser accidentalmente" 23 .

Dos aclaraciones básicas necesita el texto. En primer lugar, qué debemos entender por "posibilidad de errar accidentalmente" en la captación de las realidades carentes de composición o indivisibles. De las varias interpretaciones que se han dado, nos parecen las más plausibles tanto la que señala que "errar" en sentido accidental sería en este caso "no captar", o bien que "errar" sería "aplicar incorrectamente la noción de algo a algo que no corresponde" 24 .

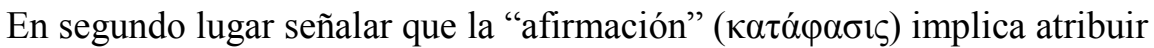
un predicado a un sujeto, mientras que la mera "enunciación" ( $\varphi \alpha ́ \sigma ı \varsigma)$ no comporta atribución alguna: no se da composición ni separación. Por este motivo en la mera enunciación no se da la verdad y la falsedad en sentido estricto.

Pero existe una discrepancia entre los dos textos que estamos estudiando.

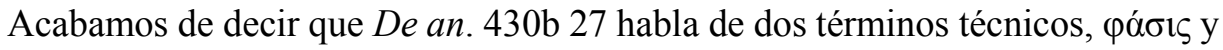

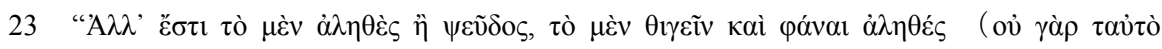

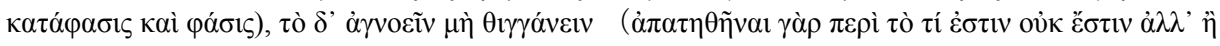

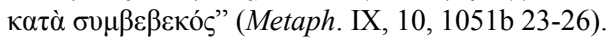

24 Sobre las varias interpretaciones véase Tomás Calvo en Aristóteles, Metafisica, ed. Valentín García Yebra (Madrid: Gredos, 1987), 391, nota 48 y Enrico Berti, "The Intellection of 'Indivisibles' according to Aristotle, De anima III 6", en Aristotle on Mind and the Senses. Proceedings of the Seventh Symposium Aristotelicum, ed. G.E.L Lloyd, Geoffrey E.R.; Owen (London-New York: Cambridge University Press, 1978), 149. 


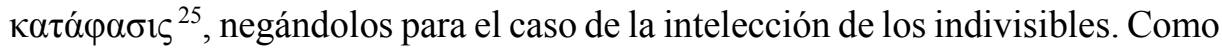

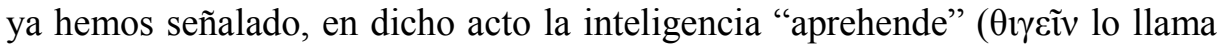
en Metaph. IX, 10, 1051b 23) o "capta" las realidades indivisibles ( $\dot{\alpha} \pi \lambda \tilde{\alpha}$ o

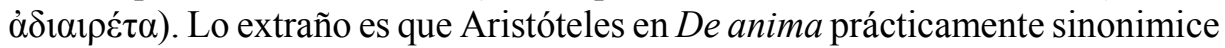

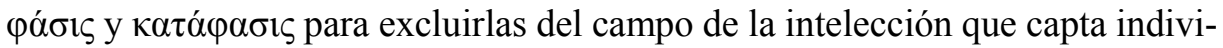

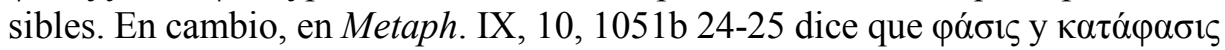
no son lo mismo, al igual que en De inter. 4, 16b 26-27 donde diferencia el discurso $(\lambda o ́ \gamma o \varsigma)$, que formaliza "enunciados" ( $(\alpha ́ \sigma ા \varsigma)$ que son partes del dis-

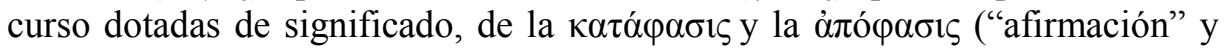
"negación") que son los juicios o proposiciones afirmativos o negativos en los cuales se predica algo de algo.

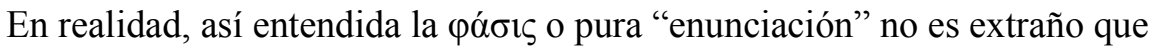
se pueda dar en el voũ como "inteligencia intuitiva", tal y como se afirma en Metaph. IX, 10, 1051b 22, pues consiste, no en un proceso de elaboración-comparación de juicio atributivo alguno, sino en el mero "decir" ( $\varphi \eta \mu$ í) un segmento indivisible del "discurso" cuya "descomposición" en meras sílabas lo volvería incomprensible. Así, como "parte mínima significativa" de lo que se puede "decir" sobre lo real resulta adecuada para manifestar lo "inmediatamente aprehendido" por la inteligencia humana. "En la afirmación ( $\kappa \alpha \dot{\alpha} \varphi \alpha \sigma \iota \varsigma)$ se atribuye un

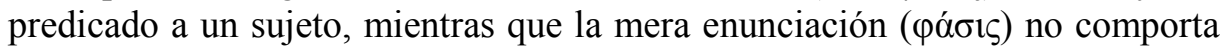
atribución ni, por tanto, composición"26.

En suma, hay dos modalidades del pensar: la del "pensamiento discursivo" abocado al lenguaje apofántico (o predicativo, del que puede decirse si es verdadero o falso) y la del que no lo es, porque no elabora juicios sobre lo real, "componiendo" "sujeto y atribuciones" 27 . Esta forma "simple" de "decir" "capta los indivisibles". Cuando, por contra, la "enunciación" se pone al servicio del "razonamiento discursivo", entra en "composición" ( $\sigma u ́ v \theta \eta \sigma ı \varsigma)$ y se confunde con la $\kappa \alpha \tau \alpha \dot{\varphi} \varphi \alpha \sigma \varsigma^{28}$.

25 Cf. De inter. 16b 26-27

26 Tomás Calvo, Aristóteles. Metafisica: 391, nota 47.

27 Estas dos modalidades del pensamiento son las que relaciona Moreau, "Aristote et la vérité antépredicative" respectivamente con la "verdad predicativa" y la "verdad antepredicativa".

28 Cf. Inés Durán Martínez, "El nous en Aristóteles: análisis léxico del término" (Tesis doctoral, Universidad Complutense de Madrid, 2002), 564-65. Se puede consultar en formato PDF en http://www.ucm.es/eprints/2288 (consulta 14 de mayo de 2019). 


\subsection{Intelección e investigación}

En el texto de Metaphysica que estamos comentando hay algo que pudiera sorprendernos. Estamos hablando de una captación en la que no cabe el error, que se da en un tiempo indivisible y que debe ser inmediata, esto es, sin mediaciones, pues es objeto de intelección (voũs). Sin embargo, Aristóteles señala: "No obstante, acerca de ellas nos preguntamos por el qué es, si son tales o no"22.

¿Habrá que contraponer intelección inmediata (voũs) e investigación? Pues parece que preguntarnos implica indagar y toda búsqueda puede fracasar. Y el fracaso es incompatible con la infalibilidad que atribuye Aristóteles a la intelección de los indivisibles.

No es preciso, sin embargo, llevar al extremo la contraposición que proponemos, pues parece perfectamente posible compatibilizar la búsqueda con la infalibilidad de la intelección. Dicho en otros términos, la infalibilidad de que hablamos no tiene porqué excluir todo tipo de indagación. Podríamos decir que el tipo de investigación que trata de averiguar si un determinado atributo pertenece a un determinado sujeto puede corresponder o no con el estado de cosas a que se refiere. Por este motivo esta investigación puede conducir a la verdad o a la falsedad del juicio en que se expresa el resultado de la indagación. En cambio, en la investigación ligada a la búsqueda de la esencia, el resultado puede ser alcanzar el conocimiento de la misma o no tener conocimiento en absoluto (ignorancia). Esta investigación es auténtica indagación, pues supone un proceso desarrollado a lo largo de un tiempo y con unas técnicas dialécticas determinadas. El que termine en una intelección infalible no implica que no haya habido un genuino proceso de búsqueda. Por tanto, conviene señalar que la infalibilidad de la intelección de que estamos hablando no implica una garantía de éxito $a$ priori, sino que la infalibilidad es una característica que pertenece a la intelección de los indivisibles cuando ésta realmente se ha dado.

Los dos tipos de indagación a que nos hemos referido en el párrafo anterior pueden encontrarse aludidos también en otro texto de la Metaphysica ${ }^{30}$ :

"Y puesto que la existencia $<$ de la cosa $>$ debe conocerse y darse, es evidente que se pregunta acerca de la materia por qué es $<$ tal cosa $>$. Por ejemplo, "¿por qué estos materiales son una casa?": porque en ellos se da la esencia de casa. $\mathrm{Y}$ "esto -o bien, este cuerpo que tiene esto- es un hombre". Por consiguiente, se pregunta por la causa de la materia (que no es otra que la forma), causa por

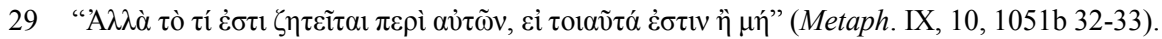

30 Cf. también An. post. II, 9 que habla de diversos modos de investigación. El comentario que ofrecemos a continuación ilustraría en lo fundamental lo dicho en An. post. II, 9. 
la que aquélla es algo. Y ésta es, por su parte, la entidad. Así pues, es evidente que, tratándose de las cosas simples, no cabe preguntar ni enseñar, sino que ha de ser otro el método de investigar acerca de ellas" ${ }^{\text {"31. }}$.

El texto afirma que la investigación del "porqué algo es aquello que es", es un tipo de investigación diferente a la que indaga "por qué un cierto sujeto tiene determinado atributo" 32 . Preguntarse "por qué algo es aquello que es" es investigar la esencia de algo. Se trata de dos tipos diferentes de investigación no solo por sus métodos, sino también por sus resultados. La investigación acerca de si un determinado sujeto posee un determinado atributo supone y parte de determinados principios (comunes y propios); puede enseñarse porque puede expresarse en un cuerpo de doctrina y puede conducir a una proposición verdadera o falsa (o verdadera para un tiempo determinado, pero no para otro ${ }^{33}$ ). Al contrario sucede con la investigación sobre qué es algo: no puede partir de principios, pues indaga precisamente un principio propio (la búsqueda de la esencia); no puede enseñarse, pues no puede reducirse a un conjunto organizado de doctrinas $\mathrm{y}$, en cuanto a su resultado, o alcanza la esencia, o bien es pura ignorancia.

Lo dicho nos convence de que la intelección de las realidades carentes de composición (o indivisibles) no tiene porqué ser un acto sencillo y directo, pues puede ser fruto de una indagación compleja y trabajosa. Muchas veces se confunden algunos términos al hablar del "intuicionismo aristotélico" (e incluso al entender otros tipos de intuicionismo). Se equipara "intuición" con "conocimiento sencillo y directo" "34. Si nos atenemos al esquema de indagación de la búsqueda de la esencia presente en An. post. II, $19^{35}$ hemos de decir que dicha investigación no tiene por qué ser sencilla (pues puede requerir una acumulación grande de experiencia anterior) ni directa (pues el alcanzar su objetivo requiere, a veces, un tortuoso camino amenazado por el vacío del no encontrar lo buscado). En la posición que defendemos a partir del estudio de Aristóteles, está lejos de nosotros conceptuar la intuición aristotélica como algo sencillo y directo. $\mathrm{Su}$ característica esencial es ser un conocimiento inmediato en el sentido de que no

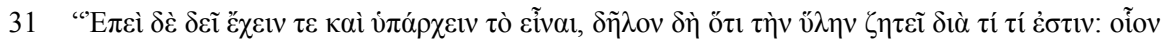

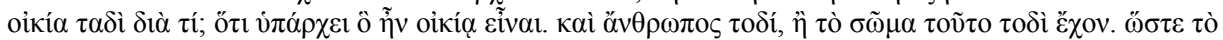

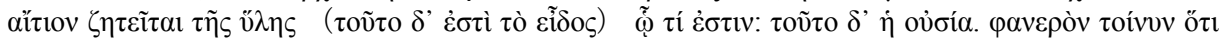

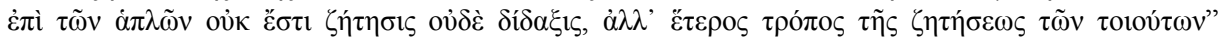
(Metaph. VII, 17, 1041b 4-11).

32 En los ejemplos de Aristóteles, "por qué el hombre es tal tipo de animal" o "por qué se da estruendo en las nubes" es decir, "por qué truena" (Metaph. VII, 17, 1041a 20-25).

33 Cf. De an. III, 6, 430b 4-5.

34 Empleamos aquí este término en un sentido amplio, no en el sentido técnico empleado por Zubiri, por ejemplo en Xavier Zubiri, Inteligencia sentiente. *Inteligencia y realidad, 67 y 257, y al que nos referiremos más adelante.

35 Véase las referencias que hacemos más adelante a este importantísimo texto. 
existe un medio en dicho conocimiento. La captación de la esencia de algo es, como lo califica Metaphysica, un acto de "tocar" $(\theta v \gamma \varepsilon \tilde{i} v)^{36}$. Y al tocar algo se entra en relación inmediata con lo tocado, aunque para llegar a esa relación haya que haber recorrido un intrincado itinerario. Pero una vez recorrido, o se está delante de la realidad (sin mediaciones) o no se está. Conocimiento inmediato se opone solo a conocimiento discursivo ${ }^{37}$.

\subsection{Intelección y tiempo}

Si existe investigación en la búsqueda de las realidades carentes de composición, ¿supone esto que el tiempo de la intelección de las mismas no será el instante, sino un proceso dilatado en el tiempo, lo cual arruinaría la tesis que estamos sosteniendo? En la segunda posibilidad habríamos de pensar en el intelecto discursivo como el adecuado a este proceso, no el voũc. Sin embargo, el texto de De an. III, 6 dice que la intelección de los indivisibles se produce en "un tiempo indivisible y por medio de un acto indivisible del alma". Matiza a continuación señalando que:

"El acto en que se intelige y el tiempo en que se intelige son, a su vez, divisibles accidentalmente; pero no porque los continuos espacial y temporal (inteligidos en ellos) se dividan, sino en la medida en que tales continuos permanecen indivisos; y es que en éstos hay algo indivisible -por más que no exista separado- que hace que el tiempo y la extensión constituyan una unidad, algo que está presente por igual en todo continuo, sea temporal o espacial" ${ }^{\prime 38}$.

El tiempo indivisible en que se intelige es divisible accidentalmente si la realidad indivisible inteligida es, a su vez, divisible en potencia, aunque actualmente no esté dividida (pues así es inteligida). El adverbio "accidentalmente" no puede entenderse en el texto en el sentido de que las realidades potencialmente divisibles, pero actualmente indivisas, que son inteligidas en un tiempo indivisible accidentalmente, pudieran ser inteligidas en tiempos sucesivos si estuvieran actualmente divididas, pues esta estrategia no nos haría salir del hecho de que, por ejemplo, las dos mitades en que se podría dividir una cierta cantidad

36 Yebra traduce "alcanzar": Aristóteles, Metafisica, 1987. Tomás Calvo traduce "captar": Aristóteles, Metafisica, 1994. La imagen vuelve en Metaph. XII, 7, 1072b 21.

37 Un estudio de estos asuntos tan competente como el realizado por Berti, cae en el error que hemos señalado (cf. Berti, "The Intellection of 'Indivisibles' according to Aristotle, De anima III 6", 150-51).

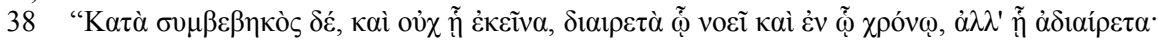

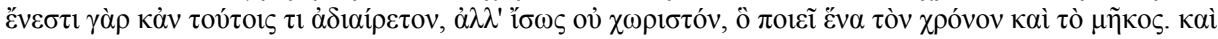

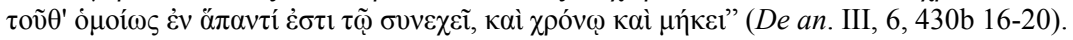


serían, a su vez, inteligidas en un tiempo indivisible, dado que ambas mitades serían actualmente indivisas. El tiempo de la intelección es solo accidentalmente divisible. De hecho es un tiempo indivisible en cuanto intelige un continuo actualmente uno "en la medida en que tales continuos permanecen indivisos", como dice el texto comentado. Lo expuesto respecto del tiempo puede trasladarse a lo que podríamos señalar sobre el acto de intelección, pues el texto se refiere por igual a ambos.

¿Podría aplicarse esta discusión a la intelección de los indivisibles según la forma? Pues parece que el texto citado se referiría exclusivamente a la intelección de los indivisibles según la cantidad ${ }^{39}$. Sin embargo puede mostrarse que dichas observaciones son perfectamente pertinentes para la intelección de los indivisibles según la forma. En efecto, en este caso el todo sería el universal y las partes, los individuos de que se predica dicho universal. Ciertamente cuando se intelige el universal se intelige en un tiempo unitario, pero esto no implica que alcanzar el universal no requiera una indagación que transcurra a lo largo de un tiempo. Esta posibilidad, no excluida en el texto que comentamos, se encuentra perfectamente representada en An. post. II, 19. Este último texto responde a cómo se conocen los principios, entendiendo esta pregunta en el doble sentido de cuál es el método por el que se llega al conocimiento de los mismos y cuál es el estatuto del conocimiento resultante. A la primera pregunta se responde señalando al método dialéctico de la inducción; la respuesta a la segunda es que se conocen por intuición. Y aquí se entiende por principio justamente el universal, es decir la esencia de algo ${ }^{40}$. No debemos olvidar que la esencia se expresa en una definición y que la definición es un principio propio. El proceso de inducción en An. post. II, 19 se compara a la reorganización de un ejército que huye en desbandada: cuando se detiene un soldado, se detiene otro y otro y así sucesivamente, de tal modo que puede volverse a reorganizar el ejército en su jerarquía primitiva. Esta jerarquía coloca a cada uno en su lugar propio. Algo así sucede, dice Aristóteles, cuando se trata de alcanzar el universal en el alma a partir de los singulares con la intervención (no entendida en sentido sucesivo temporal) de los sentidos, la memoria, la experiencia y el intelecto.

Los sentidos son, según Aristóteles, capaces de percibir cualidades sensibles. No pueden ser afectados por propiedades que no sean sensibles en sentido

39 La observación de Tomás Calvo (Aristóteles, Metafísica, 1994, 236-37, nota 82.) de que las anteriores precisiones no se refieren a la intelección de los indivisibles según la forma no nos parecen pertinentes por lo que diremos a continuación apoyándonos en An. post. II, 19.

40 En Jesús Manuel Conderana Cerrillo, El conocimiento de los principios prácticos en Aristóteles, (Salamanca: Publicaciones de la Universidad Pontificia de Salamanca, 2002), 179-82 se muestra que el texto puede leerse también entendiendo como principios los principios comunes. 
estricto: propiamente hablando, no pueden distinguir entre caballos y hombres ni reconocer un ser determinado en cuanto hombre. Pueden distinguir sólo figuras de diferentes tamaños, formas, colores, olores... Desde luego, la percepción sensible, unida a la memoria, es suficiente para los animales. Mediante ellas un perro puede distinguir entre su amo y un caballo sin necesidad de distinguir a su amo en cuanto hombre ni al caballo en cuanto caballo (De an. III, 4, 429b 1416). Pero estas capacidades no bastan para explicar el conocimiento humano. En el hombre, la percepción está imbuida de intelecto. Por eso puede decir Aristóteles que el discernir se realiza o mediante otra facultad o mediante la misma (la percepción) pero dispuesta de otro modo (De an. III, 4, 429b 13. 20-21). Ya que sólo la razón puede discriminar entre esencias, se entiende que esa otra facultad aludida debe ser la razón que colabora con la percepción conociendo los sensibles por accidente como "hombre", "caballo" o "hijo de Diares": se trata de realidades no sensibles que podemos conocer partiendo de la experiencia sensible.

Los sentidos son condición necesaria para el conocimiento. Sin ellos nunca llegaríamos a percatarnos de la presencia del hijo de Diares. Pero los sentidos no son suficientes. Sin la inteligencia no reconoceríamos esa mancha blanca de ahí como el hijo de Diares. Percibimos accidentalmente determinadas substancias, pero no percibimos que son algo individual o que pertenecen a determinada especie o clase. Esto último lo conocemos exclusivamente mediante la inteligencia. Si tomamos en serio la distinción entre los sensibles percibidos directamente por los sentidos (propios y comunes) y los sensibles por accidente, es evidente que el conocimiento de estos últimos no puede resultar de la simple combinación, selección o manipulación de los sensibles sujetos a percepción directa, como podría pretender alguna versión empirista de la génesis de los conceptos. Los sensibles por accidente están en los objetos percibidos, pero es trabajo del intelecto aprehender las formas en las imágenes (De an. III, 7, 431b 2).

Aristóteles sintetiza la solución expuesta diciendo que la percepción es ya de "hombre" y no del "hombre Calias". La percepción, aun siendo de lo individual, nos da desde el primer momento también un cierto universal. Lo que el alma retiene en primer lugar no es un individuo conocido por los sentidos aquí y ahora en todos sus particulares irrepetibles. Esto no podría dar lugar nunca a un universal. Lo que se percibe en lo individual es una infima species 
( $\dot{\alpha} \delta 1 \alpha ́(\varphi o \rho o v)$, que es un universal, el primer universal. "Pues la sensación es de lo singular, pero lo que se percibe es ya un universal" $"$.

El proceso de universalización no se detiene en la aprehensión de un primer universal. Lo sensible particular es un caso de un tipo. Percibimos este hombre concreto (un caso), pero la percepción es de "hombre" (un tipo, una clase). Los individuos concretos son representantes de más de una clase. Calias no sólo es hombre, sino también bípedo, animal y ser vivo. Según Aristóteles, la relación entre la percepción de un individuo (Calias) y la aprehensión de su especie (hombre), es la misma que entre la aprehensión de la especie y la aprehensión del género al que pertenece (animal). Aunque entendemos que son diferentes relaciones la pertenencia de un individuo a una clase y la inclusión de una en otra, Aristóteles no las distingue, como tampoco parece hacerlo Platón ${ }^{42}$. Aristóteles usa el individuo particular (Calias) sea como algo individual, sea como integrante de una clase (hombres). Desde este segundo punto de vista la percepción es aprehensión de una especie realizada en un individuo particular. Por ello el detenerse alguna de las cosas indiferenciadas en el alma es ya la aparición de lo universal en el alma por vez primera: "Calias-hombre" es percibido como "hombre". Puesto que Calias es un miembro de todas las clases implicadas, la percepción de Calias puede servir como base para la aprehensión de todos esos universales, porque todas esas clases se diferencian por su grado de universalización. Cuando un universal aumenta en extensión (se pasa, por ejemplo, de "animal" a "ser vivo"), disminuye en comprensión: muchas de las notas características de "animal" se pierden al hablar de "ser vivo".

De este modo podemos entender el símil de An. Post. II, 19 entre el proceso cognitivo y la desbandada en una batalla en la que, al pararse un soldado, se para otro y así sucesivamente hasta que se reorganiza de nuevo toda la formación. En ambos casos se da un movimiento que va de los individuos concretos a la reorganización completa de todo el conjunto. Durante la desbandada cada soldado es un ser individual, como lo son los sensibles particulares aprehendidos inicialmente por la sensación. Pero cuando empiezan a detenerse y a reorganizarse en sus batallones, grupos y subgrupos, se rehace un todo ordenado donde los individuos quedan integrados. Análogamente, la universalización a partir de la experiencia organiza las imágenes singulares en agrupaciones de géneros y

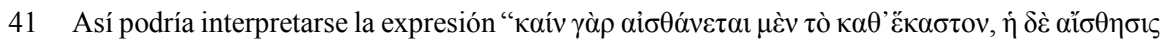

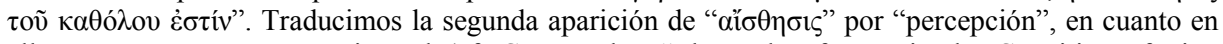
ella está ya supuesto un universal (cf. C. H Kahn, "The Role of nous in the Cognition of First Principles", en Aristotle on Sience. The Posterior Analytics, ed. Enrico Berti (Editrice Antenore, 1981), 405, nota 21).

42 Cf. Modrak, Aristotle. The Power of Perception, 223, nota 33. 
especies. Cuando el ejército ha sido completamente reorganizado, cada soldado aparece en el lugar y rango que le corresponde. Entonces ya no cuenta como individuo concreto: los individuos de un mismo escalafón son seres intercambiables. Algo análogo sucede en el pensamiento: la imagen mental que sirve para pensar un determinado concepto es un ejemplo arbitrario de ese género concreto. Cualquier otra imagen mental perteneciente al mismo género serviría. Si se piensa, por ejemplo, en "triángulo", cualquier imagen de triángulo sirve. Un ejército en formación que depende de un mando único es análogo al pensamiento organizado bajo un principio universal. Igual que no existe un ejército sin soldados, tampoco existen los universales sin los particulares aprehendidos por la sensibilidad.

Lo dicho hasta aquí sobre la intelección de los universales se confirma en un texto de Metaphysica donde se compara la intelección del intelecto divino con la del intelecto humano respecto del tiempo ${ }^{43}$. El problema planteado es si el objeto de la intelección divina es compuesto ( $\sigma u v \theta \varepsilon \tau o ́ v)$ o no. Si fuera compuesto, la intelección divina estaría en proceso de cambio pues habría de pasar de una parte a otra del objeto, además de implicar tiempo, lo que contradice la esencia divina que es acto. Se concluye, pues que el objeto de la inteligencia divina ha de ser indivisible. Pero, como ya sabemos por De an. III, 6, esta indivisibilidad puede entenderse de dos modos:

a) Lo inteligido es una realidad indivisible sólo actualmente, pero potencialmente divisible. Se trata de una esencia común a varios individuos. Se trata de un universal que, como hemos visto comentando An. post. II, 19, aunque es capaz de "dividirse" en cada singular, posee unidad actual. Hablamos en este caso de las esencias de realidades materiales, objeto de la intelección del intelecto humano.

b) Lo inteligido es una realidad indivisible actual y potencialmente. En este caso se trata de una esencia que no es común a varios individuos, sino que ella misma es individual y que no puede ser dividida de ningún modo. Es el caso de la esencia divina, objeto único de la intelección del dios aristotélico, como es bien sabido.

A pesar de las diferencias (por sus objetos) entre ambos tipos de inteligencia, existe, sin embargo, una cierta semejanza respecto del tiempo de la intelección, según constata el final del capítulo que comentamos:

43 Metaph. XII, 9, 1075a 5-10; cf. Berti, "The Intellection of 'Indivisibles' according to Aristotle, De anima III 6", 151-54. 


\begin{abstract}
"Queda aún una aporía: si lo pensado es compuesto, en cuyo caso (el pensamiento) cambiaría de una parte a otra del todo. ¿O, más bien, es indivisible todo lo que no tiene materia, y así como se encuentra en ciertos momentos el entendimiento humano, o incluso el de los compuestos (pues no alcanza su bien en esta parte o en esta otra, sino que alcanza su bien supremo, que es distinto de él, en un todo completo), así se encuentra el pensamiento mismo de sí mismo por toda la eternidad?"44.
\end{abstract}

En efecto, la diferencia entre ambos entendimientos está en que el entendimiento humano solo se encuentra en ciertos momentos en la misma condición en la que el divino se encuentra eternamente. ¿A qué momentos privilegiados ${ }^{45}$ se refiere el texto? El texto mismo parece responder que se trata de los momentos en que el entendimiento humano alcanza un todo completo: el universal. Y esto sucede solo en ciertos momentos, puesto que para alcanzar el universal en un tiempo indivisible, el entendimiento ha de fatigar en el proceso, dilatado en el tiempo, de captar lo universal en lo singular por los estadios de la sensación, memoria y experiencia, como hemos visto comentando An. post. II, 19. Al final de dicho proceso, el intelecto alcanza el universal, ya no por un proceso, sino de manera inmediata, en una cierta inmutable visión semejante a la intelección divina que, como hemos señalado, no necesita ningún proceso previo para encontrase siempre en dicha visión directa e inmediata.

Así podemos aclarar el tiempo en que se da la intelección humana de los indivisibles: dicha intelección se da en un tiempo unitario, indivisible, un tiempo en el que no hay proceso, es decir, no hay sucesión de estadios. Pero esta intelección viene precedida por un proceso dilatado en el tiempo que implica sucesión en el entendimiento humano.

\title{
3. MODOS DE INTELECCIÓN Y VERDAD ANTEPREDICATIVA
}

Nos queda concluir esta parte de nuestra investigación planteando tres cuestiones claves: cómo se conocen cierto tipo de sensibles, cómo se conocen los indivisibles y qué relación existe entre este conocimiento y la verdad antepredicativa. Propiamente no se trata de añadir nada nuevo, sino más bien de recoger en síntesis aquello que hemos tratado de mostrar en lo que llevamos dicho.

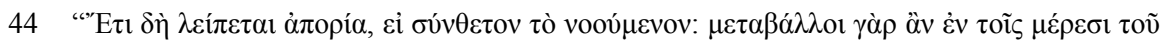

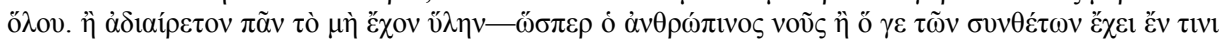

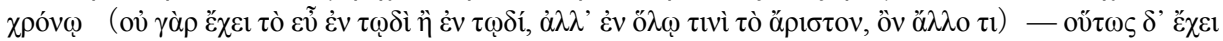

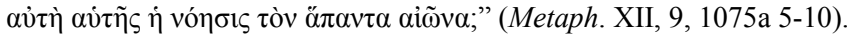

45 Privilegiados, pues es en ellos en los que alcanza su bien. 
Partamos de las afirmaciones aristotélicas que justifican lo que vamos a decir a continuación. Al final de De an. III, 6 podemos leer:

"Pero así como la visión es verdadera cuando se trata del sensible propio pero no siempre es verdadera cuando se trata de si lo blanco es un hombre o no, así también sucede en relación con los objetos separados de la materia" ${ }^{46}$.

Leyendo el texto en el conjunto del capítulo y a la luz de la interpretación que sostenemos en estas páginas podemos hacer algunas afirmaciones que nos sirvan de conclusión de lo dicho hasta aquí.

El texto presenta una comparación entre el tipo de verdad que se alcanza al conocer los sensibles propios y el que se alcanza al conocer "objetos separados de la materia" 47 . La asimilación entre ambos modos de conocimiento y el tipo de verdad que alcanzan no es metafórica. Según hemos sostenido, a ambos modos de conocimiento se pueden atribuir algunas características comunes. En primer lugar se alcanza una verdad de modo infalible de manera que no existe posibilidad de error en sentido propio: el ojo capta lo blanco o no lo capta; el intelecto conoce una forma o no la conoce.

En segundo lugar, que exista infalibilidad se debe en los dos casos también al mismo motivo: la percepción y el intelecto se encuentran delante de unidades que han de ser simplemente descubiertas. El error aparece, como el mismo texto señala, cuando las unidades descubiertas se hacen entrar en algún tipo de composición, como cuando se dice si lo blanco visto es un hombre o no (donde "lo blanco" sería objeto de percepción sensible y "hombre", ejemplo de forma, o sea, de "objeto separado de la materia", en palabras del texto).

En tercer lugar ambos modos de conocimiento son inmediatos, es decir sin medio alguno que permita alcanzar la conclusión. La verdad conocida no es conclusión, sino punto de partida de conclusiones (principios). Por eso lo conocido aquí puede ser material para una síntesis, pero no es él mismo fruto de una síntesis. Lo dicho no significa que la verdad se alcance sin esfuerzo o sin algún tipo de indagación. Ya hemos explicado que hay que diferenciar entre que este conocimiento sea sencillo y directo, que no lo es, y que sea inmediato, que sí lo es.

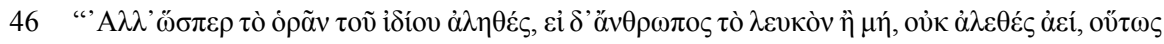

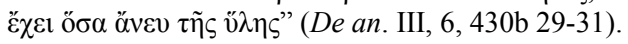

47 El hecho de que en la última línea del capítulo Aristóteles califique a todas estas cosas de las que hay intelección como realidades "sin materia", no significa que sean inmateriales. Todas las esencias son inmateriales, pero por ser universales no son substancias separadas: no pueden existir independientemente de las realidades materiales. Hemos de pensar que se trata de las esencias inmateriales de las realidades materiales. 
Dicho lo cual nos parece pertinente concluir que nos encontramos ante un tipo de conocimiento que podemos calificar como "intuitivo". En el vocabulario aristotélico encontramos dos términos para referirse a este concepto $\alpha$ li $\sigma \theta \eta \varepsilon \sigma ı \varsigma$ y voũ $\varsigma^{48}$. Con el primero designa a la percepción sensible como conocimiento inmediato. En este sentido podríamos hablar de una "percepción" de los sensibles propios entendida como un conocimiento inmediato de los mismos. Son ejemplos de la misma la percepción de determinado color, sabor o textura cuando son percibidos por los sentidos adecuados: la vista, el gusto o el tacto respectivamente.

Parece que del mismo modo que habría una intuición sensible de los sensibles propios, habría también una "percepción intelectual" de los indivisibles objetos del voṽs. Si revisamos los cinco tipos de indivisibles que presenta el $D e$ anima para aplicarles lo que acabamos de decir, nos damos cuenta, en primer lugar, que los cinco tipos podrían clasificarse, desde el punto de vista del cómo son conocidos, en dos grupos. Un tipo de indivisibles se conocería recta e inmediatamente. Nos referimos a los indivisibles según la cantidad, según la forma y los que carecen de contrario. Así se conoce la línea, la esencia de hombre y así se conoce el dios aristotélico a sí mismo.

El otro grupo de indivisibles se conocería también inmediatamente, como no puede ser de otro modo, pero en manera, por así decir, oblicua. Es decir, para llegar a conocerlos se precisaría conocer antes otro indivisible. Se trata del conocimiento de los indivisibles según la privación. Para conocer el elemento privativo hay que conocer primero el elemento positivo. Así, una vez conocido lo bueno, es posible llegar inmediatamente al conocimiento de lo malo, como su privación que está contenida en potencia en el elemento positivo. Y como el intelecto es en potencia ambos contrarios, una vez presente en él el elemento positivo, puede conocer el privativo.

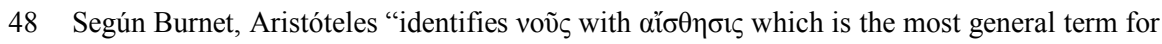
immediate perception whether sensous or intellectual (cf. EN VI, 8, 1142a 27)": John Burnet, The Ethics of Aristotle (London: Methuen and Co., 1900), XXXVII-XXXVIII. Sobre la validez de esta equiparación puede consultarse con fruto los capítulos $3^{\circ}$ y $4^{\circ}$ de la parte III de Durán Martínez, "El nous en Aristóteles: análisis léxico del término". Ver también EN VI, 11, 143b 5: cf. Conderana Cerrillo, El conocimiento de los principios prácticos en Aristóteles, 334-44. El intuicionismo que se atribuye a Aristóteles a partir de su método de "salvar las apariencias" de las convicciones del sentido común (EN VII, 1, 1145b 2-7) contiene una dificultad magníficamente señalada por Juan Miguel Palacios, "Vida moral y saber moral", en El deber gozoso de filosofar: homenaje a Miguel García-Baró, ed. A. Serrano de Haro (Salamanca: Sígueme, 2018), 371-75. Para la Ética a Nicómaco seguimos: Aristóteles, Ética a Nicómaco, ed. María Araujo y Julián Marías (Madrid: Centro de Estudios Políticos y Constitucionales, 1989). 
Es interesante constatar que como ejemplo de indivisibles según la privación aparece lo negro como privación de lo blanco. Y lo blanco es un sensible propio. Esto nos lleva a pensar que no podemos establecer una separación tajante entre sentidos e inteligencia, como si los sentidos humanos pudieran funcionar al margen de la inteligencia, como ya hemos señalado al comentar $A n$. post. II, $19^{49}$.

Una última observación: tanto los sensibles propios como todas las categorías de indivisibles son principios para Aristóteles en cuanto puntos de partida absolutos para la construcción de juicios. Y de los principios no hay razonamiento, sino voṽ (An. post. II, 19, 100b 5-17).

\section{LA VERDAD REAL EN ZUBIRI}

El tema de la verdad real aparece en la obra zubiriana no solo con frecuencia, sino también con una importancia que sería difícil exagerar ${ }^{50}$. El mismo Zubiri señala el papel clave de la verdad real al indicar que: "Podemos servirnos de la verdad real como de hilo conductor para entrar en la estructura de la realidad"51.

Ciertamente no es éste el hilo conductor de su exposición (ni en Sobre la esencia ni en otros escritos), pero a poco que el lector se adentre en la obra zubiriana, inmediatamente se da cuenta de la cantidad de conexiones temáticas que se entrecruzan en el tema de la verdad real. Nuestro objetivo en estas páginas no es explicar ni siquiera someramente la riqueza de este concepto. La guía de nuestra exposición será la comparación con la verdad antepredicativa en Aristóteles, tal y como acabamos de exponerla en las páginas anteriores. La tesis que sostendremos es que existen similitudes de fondo al tiempo que, como no podía ser menos, también profundas diferencias. En todo caso, nuestro punto de vista fundamental será señalar las semejanzas mostrando que, a pesar de las graves acusaciones vertidas contra Aristóteles, el planteamiento zubiriano de la verdad real está inspirado en lo ya dicho explícitamente por Aristóteles en algunos aspectos relevantes.

49 Ver el apartado 1.2.4 "Intelección y tiempo".

50 Juan A. Nicolás afirma que es una cuestión con la que se ha debatido prácticamente a lo largo de toda su vida (cf. Introducción a Xavier Zubiri, El hombre y la verdad, IV-V). En nuestro estudio tendremos en cuenta fundamentalmente las siguientes obras: Xavier Zubiri, Sobre la esencia, Inteligencia y realidad, Inteligencia y logos y de manera secundaria El hombre y la verdad y El hombre y Dios.

51 Zubiri, Sobre la esencia, 124. 


\section{1. ¿QUÉ ES LA VERDAD REAL?}

Como es bien sabido ${ }^{52}$, la intelección es mera actualización de lo real como real. Lo que la mera actualización de lo real añade a la realidad es su verdad. ¿Significa esto que la verdad es cosa de la inteligencia, como en Aristóteles? No exactamente, aunque es cierto que a primera vista la verdad parece ser una cualidad de la afirmación. Pero no es así, porque la afirmación es tan sólo un modo de intelección ${ }^{53}$.

¿Qué entender entonces por verdad? La intelección consiste formalmente en aprehender algo como real, y esta intelección tiene su verdad: verdad es la intelección en cuanto aprehende lo real presente como real. La verdad añade, pues, a la realidad su mera actualización intelectiva. No añade, en cambio, nada a la realidad en las notas. Por tanto podemos decir que "verdad es pura y simplemente el momento de la real presencia intelectiva de la realidad"54.

El marco en el que nos moveremos es, pues, el de la verdad que, como acabamos de ver, corresponde a toda intelección en cuanto ésta es siempre "el momento de real presencia intelectiva de la realidad". Pero nos interesa desentrañar qué entender por la verdad radical, por la verdad que corresponde a la intelección sentiente en su modo radical y primario y, en consecuencia, buscamos la índole primaria y radical de la actualización sentiente de lo real que corresponderá a esa verdad radical y primaria que buscamos. Pues bien, según $\mathrm{Zu}-$ biri, la intelección sentiente en su forma primaria y radical es aquella en que lo aprehendido lo es en y por sí mismo:

“Ahora bien, en esta actualización sentiente lo aprehendido lo es 'de suyo'. Y este momento de formalidad del 'de suyo' es un momento de la cosa anterior (prius) a su propio estar aprehendida. $\mathrm{Y}$ en esto consiste justamente su realidad. Pero claro está, este 'de suyo' anterior a la aprehensión está, sin embargo, aprehendido en su propia anterioridad; esto es, está presente en la intelección sentiente. Pues bien, este 'de suyo' en cuanto anterior a la aprehensión es realidad. Y este 'de suyo' en cuanto presente en la aprehensión es justamente su verdad. Verdad es realidad presente en intelección en

52 Seguimos en nuestra exposición principalmente el capítulo VII de Xavier Zubiri, Inteligencia y realidad. Es básicamente idéntico a la exposición del capítulo 8 de Xavier Zubiri, Sobre la esencia. Según Antonio Pintor-Ramos, Nudos en la filosofia de Zubiri (Salamanca: Publicaciones de la Universidad Pontificia de Salamanca, 2006), 227-28 en Sobre la esencia hay una doctrina definitiva sobre la verdad real, pero incompleta. Lo que faltaría sería la doctrina definida de la aprehensión primordial de realidad que sí está presente en la trilogía.

53 Sobre las formas y los modos de afirmación véase Xavier Zubiri, Inteligencia y logos (Madrid: Alianza Editorial, 1982), capítulo 5 § 2 y 3.

54 Zubiri, Inteligencia sentiente. *Inteligencia y realidad, 231. 
cuanto está realmente presente en ella. La verdad primaria y radical de la intelección sentiente no se identifica con la realidad. Lo que añade esta verdad primaria a la realidad es una especie de ratificación según la cual lo aprehendido como real está presente en su aprehensión misma: es justo ratificación del 'de suyo'. Ratificación es la forma primaria y radical de la verdad de la intelección sentiente. Es lo que yo llamo verdad real”"55.

A continuación explica Zubiri los dos términos que entran a formar parte de "verdad real":

- Es verdad porque no es idéntica a la realidad. Realidad es formalidad de la cosa. Verdad es cualidad de la intelección en cuanto en la intelección está presente lo real. Verdad real es ratificación de la realidad.

- Es real porque es la realidad misma la que está en esta verdad; es lo real mismo que verdadea.

Una característica muy sobresaliente de la verdad real es la imposibilidad de error que implica. Zubiri la formula diciendo que "La verdad real no se contrapone al error, sencillamente porque la intelección primaria de lo real no admite la posibilidad de error" 56 .

Si entendemos bien lo afirmado por Zubiri, en la aprehensión primordial de realidad, en su modalidad radical y primaria, como veremos en el apartado siguiente, no cabe la posibilidad de error. ¿Cuál es la explicación? En Sobre la esencia (p. 127) se dice que el error se puede dar al tratar de averiguar lo que en cada cosa sea su realidad simpliciter y verdadera. No cabe error en la mera remisión a esta realidad simpliciter, a algo que como "cosa" está actualizado en sus notas como momentos reales suyos. La explicación de Inteligencia y realidad (pp. 236-237) es básicamente la misma. Teniendo en cuenta que toda verdad dual se halla fundada en verdad real $^{57}$ y que en la verdad dual sí existe posibilidad de error dado que en esta verdad se va más allá de la aprehensión primordial de realidad para averiguar qué sea lo aprehendido en realidad, habrá que decir que la existencia misma de la posibilidad de error pende del hecho de la existencia de la verdad real. 


\section{APREHENSIÓN PRIMORDIAL DE REALIDAD}

Inteligencia y realidad, la primera parte de Inteligencia sentiente, podría haber acabado en el capítulo VII. El capítulo VIII es una explicación pormenorizada de algo que ya estaba dicho en los capítulos anteriores ${ }^{58}$ : que existen diversos modos de intelección y que existe uno primario y radical que es el que se analiza en el citado capítulo. El capítulo IX es un anticipo de las dos siguientes partes de la obra y el capítulo X podría haberse incluido como una parte del capítulo $\mathrm{IV}^{59}$. Lo dicho no significa que, por motivos expositivos y de claridad, los tres capítulos citados hagan de broche adecuadísimo a la conclusión de esta primera parte.

Pero tal vez haya una razón más y de más calado para hacer del capítulo VIII algo más que un apéndice "pedagógico" o aclaratorio. Pintor-Ramos ${ }^{60}$ ha mostrado con claridad que la novedad de Inteligencia sentiente estaría en la perfecta delimitación del acto de aprehensión primordial de realidad, cosa que no se da en los escritos anteriores. Así que ésta parece ser una razón suficiente para incluir el capítulo VIII que será para los lectores de Zubiri una pieza clave para penetrar más a fondo en la compresión de la verdad real, admitido que la relación entre verdad real y aprehensión primordial de realidad es constitutiva. Y no puede ser de otro modo. Como hemos visto en el apartado anterior, la verdad primaria y radical es la verdad real y el modo primario y radical de intelección es la aprehensión primordial de realidad ${ }^{61}$. Y la verdad real es la ratificación de que lo aprehendido como real está presente en su aprehensión misma.

Perfilada por Zubiri la aprehensión primordial de realidad y su relación constitutiva con la verdad real, no tendríamos ya solo una doctrina sólida y definitiva de la verdad real (que ya teníamos en Sobre la esencia), sino además una doctrina completa ${ }^{62}$. Pero, ¿en qué consiste esta aprehensión primordial de

58 "Todo está ya dicho en los capítulos anteriores" (ibidem 247). La justificación explícita del capítulo dada en la página citada está en deshacer un equívoco: que, al hablar de inteligencia sentiente, el lector se deje llevar a la idea de que "el sentir es ciertamente un momento de la intelección, olvidando, sin embargo, que este sentir es en sí mismo intelectivo".

59 Ibidem 282.

60 Véase Pintor-Ramos, Nudos en la filosofía de Zubiri, capítulo V, especialmente las páginas 227-231.

61 Zubiri emplea esos dos mismos calificativos y en el mismo orden para referirse a la verdad real (Xavier Zubiri, Inteligencia sentiente. *Inteligencia y realidad, 233) y para la aprehensión primordial de realidad (ibidem 247).

62 Cf. Pintor-Ramos, Nudos en la filosofia de Zubiri, 228. Pintor-Ramos da razones teoréticas para explicar por qué el hecho de que exista una doctrina sólida y definitiva sobre la verdad en Sobre la esencia no es contradictorio con que la doctrina sea incompleta. Podría haber, además, una razón de biografia intelectual de Zubiri para que esta doctrina fuera incompleta en este momento: pensando que el núcleo de temas de la verdad real (fundamento de las demás verdades, ausencia de error, simplicidad, 
realidad? Es formalmente intelección y como tal, aprehensión de realidad en y por sí misma. Toda intelección consiste en última instancia en esto, lo que significa que existen diversos modos de intelección, todos ellos "montados" de una u otra forma, sobre la intelección de lo real en y por sí mismo. Esto quiere decir que, existiendo modos diferentes de intelección, la intelección está modalizada. Básicamente existirán dos modalizaciones: primaria (una) y varias ulteriores ${ }^{63}$. Pero a nosotros nos interesa fijarnos en la modalidad primaria y radical de intelección (de aprehensión de realidad en y por sí misma).

La modalidad primaria y radical de la aprehensión de realidad es la aprehensión de algo en y por sí mismo "solamente" como algo en y por sí mismo. Zubiri la llama aprehensión primordial de realidad. En apretada síntesis diremos que el acto constitutivo de dicha aprehensión primordial de realidad (que no es un acto, sino un modo del acto de intelección) está modalizado en intelección atentiva (por la que nos fijamos solo en una nota, o en un todo como todo). La atención tiene dos momentos: centración (por el que me centro en lo aprehendido) y precisión (por el que lo que no está aprehendido como centro queda al margen de la aprehensión y queda como im-preciso, es un sentido etimológico explicado con detalle por Zubiri).

Puede decirse que, en la aprehensión primordial de realidad como modalización primaria y radical de la intelección sentiente, lo aprehendido lo es precisivamente en intelección atentiva (estas dos últimas notas especifican el "solamente" del que hemos partido).

Zubiri, además de preguntarse por el acto constitutivo de la aprehensión primordial de realidad, se pregunta por cuál es la indole de la actualidad de lo inteligido en este modo. De nuevo en síntesis la respuesta de Zubiri es que la actualidad compete a lo real mismo y lo real tiene diversas respectividades formales, por lo que los diversos modos de actualización dependen de los diversos modos de actualidad de lo real. A la intelección de algo "solamente" como real en y por sí mismo corresponde un modo de actualización en intelección atentiva, como hemos visto. Pues bien, este modo de actualidad es formalmente "retención". A este modo de actualidad lo llama Zubiri "retinencia" porque la actualidad en modo de "solamente" nos retiene en su propia realidad, nos retiene en su aprehensión: "Reticencia es el modo positivo y primario de actualidad" [En conclusión:] "En la aprehensión primordial de realidad quedamos, pues,

captación inmediata) está elaborado a partir de la meditación de la "verdad antepredicativa" en Aristóteles. De este modo una doctrina de la verdad real en Zubiri podría ser definitiva y sólida, pero incompleta al faltar un elemento (aprehensión primordial de realidad) que le dé su encaje en una nueva compresión de la intelección y que Zubiri elaborará más tarde.

63 Zubiri, Inteligencia sentiente. *Inteligencia y realidad, capítulo IX. 
atentivamente retenidos por lo real en su realidad propia: es la esencia completa de la aprehensión primordial de realidad" ${ }^{64}$.

Después de esta descripción de la "esencia" de lo que es la aprehensión primordial de realidad, conviene que nos detengamos en tres características suyas que le competen por el hecho de ser aprehensión radical de realidad. En la aprehensión primordial de realidad, la formalidad de realidad está aprehendida:

1. Directamente: no está aprehendida a través de representaciones o imágenes.

2. Inmediatamente: aprehendida no en virtud de otros actos aprehensivos o de razonamientos o inferencias.

3. Unitariamente: aunque lo real puede tener y tiene una gran riqueza de contenido, dicho contenido está aprehendido en unidad, como un todo ${ }^{65}$.

\section{VERDAD REAL Y APREHENSIÓN PRIMORDIAL DE REALIDAD}

Partimos de la afirmación de que la relación entre verdad y aprehensión primordial de realidad es constitutiva. Esta conexión clave la establece Zubiri al señalar que: "En la intelección sentiente la verdad se halla en esa primaria forma que es la impresión de realidad. La verdad de esta actualidad impresiva de lo real en y por sí misma es justo la verdad real" ${ }^{\prime 66}$.

Pero hay que tener en cuenta que la aprehensión primordial de realidad es el modo radical y primario de intelección (Inteligencia y realidad, 242). Por tanto la verdad real será la actualidad intelectiva de la impresión primordial de realidad en cuanto tal. La consecuencia inmediata de lo dicho es que la verdad real consiste en una ratificación (Sobre la esencia, 124) en la cual no se sale de la cosa real misma aprehendida en aprehensión primordial de realidad en y por sí misma. En esta verdad no hay nada concebido ni afirmado, sino que está solo lo real actualizado como real y ratificado como tal. Por eso puede llamarla también Zubiri "verdad simple" (Inteligencia y realidad, 235. 237). Se trata de una verdad simple porque no hay, como sucede en la verdad dual, dos términos primariamente ajenos entre sí; por una parte la cosa real y por otra su concepto, su afirmación y su razón (Inteligencia y realidad, 235). Hay un solo término, la cosa real en sus dos momentos: su actualidad propia y su propia ratificación.

64 Ibidem 262.

65 Cf. ibidem 65. 257.

66 Ibidem 234. 
Nos preguntamos si habría alguna expresión lingüística de lo aprehendido en la verdad real. Tengamos en cuenta que:

"La intelección tiene distintos modos, esto es hay distintos modos de mera actualización de lo real. Hay un modo primario y radical, la aprehensión de lo real actualizado en y por sí mismo: es lo que llamo aprehensión primordial de lo real"67.

Si esto es así, lo que está claro es que la aprehensión primordial de realidad, en cuanto modo primario y radical de la aprehensión de lo real, es una aprehensión antepredicativa, desde luego, pero también prelógica en cuanto anterior a toda intervención del logos. Esta última afirmación queda clara desde la diferenciación básica que Zubiri establece entre la primera y más básica forma de la afirmación: el juicio posicional. En las páginas dedicadas al esclarecimiento de dicho juicio, Zubiri presenta una comparación entre la aprehensión primordial de realidad y el juicio posicional que puede resumirse en la siguiente tabla:

\section{Comparación entre la aprehensión primordial de realidad y el juicio posicional}

\begin{tabular}{|l|l|}
\hline \multicolumn{1}{|c|}{ Aprehensión primordial de realidad } & \multicolumn{1}{|c|}{ Juicio posicional } \\
\hline $\begin{array}{l}\text { Tenemos lo real aprehendido que llena in- } \\
\text { mediatamente el campo de "la" realidad. }\end{array}$ & $\begin{array}{l}\text { Esto real es inteligido como realiza- } \\
\text { ción de algo ya aprehendido en simple } \\
\text { aprehensión (como realización del } \\
\text { fuego, por ejemplo). }\end{array}$ \\
\hline Es aprehensión. & Es intelección. \\
\hline Es inmediata. & $\begin{array}{l}\text { Tenemos lo real inteligido como reali- } \\
\text { zación del fuego o de la lluvia. }\end{array}$ \\
\hline $\begin{array}{l}\text { Es aprehensión de la cosa real en y por sí } \\
\text { misma como real sin necesidad de afirmar o } \\
\text { juzgar. }\end{array}$ & $\begin{array}{l}\text { En esta intelección se afirma lo que es } \\
\text { en realidad aquello que se ha aprehen- } \\
\text { dido como real (en aprehensión pri- } \\
\text { mordial), por ejemplo al abrir la ven- } \\
\text { tana. } \\
\text { En esta posición se pone lo real } \\
\text { aprehendido entero como realización. }\end{array}$ \\
\hline $\begin{array}{l}\text { No hay nombre ninguno: es la mera } \\
\text { aprehensión de la realidad de lo real. }\end{array}$ & $\begin{array}{l}\text { Se expresa con un solo nombre sus- } \\
\text { tantivo en connotación afirmativa } \\
\text { (que se expresa en la entonación, por } \\
\text { ejemplo exclamación). }\end{array}$ \\
\hline
\end{tabular}

67 Ibidem 14. 
Dado que la verdad real y la aprehensión primordial de realidad son el fundamento y la raíz de toda otra forma de intelección, podríamos suponer que el estadio anterior -si se nos permite hablar así- a la primera y más básica forma de juicio (que implica ya una cierta dualidad en la verdad y en la aprehensión) habría de corresponder al estadio de la aprehensión primordial de la realidad en toda su radicalidad. Podría sugerirse que en Zubiri habría también una expresión lingüística de lo aprehendido en la aprehensión primordial de realidad que sería la mera enunciación, por ejemplo "fuego" (algo distinto al hecho de abrir la ventana y exclamar "¡fuego!", donde ya hay una primera intervención del logos). Pero esta posibilidad está explícitamente negada, como refleja el cuadro anterior $^{68}$.

\section{VERDAD ANTEPREDICATIVA VERSUS VERDAD REAL}

Nos habíamos propuesto establecer algunos puntos de confluencia y de divergencia entre la aristotélica verdad antepredicativa y la zubiriana verdad real. Ha llegado ese momento, después de haber expuesto lo relevante de ambos conceptos. No pretendemos, ni mucho menos, agotar el tema planteado. Trataremos solo de señalar aquellas semejanzas y discrepancias más sobresalientes, dejando para otra ocasión tres direcciones que nos ofrece el trabajo que hemos emprendido: profundizar en los débitos de Zubiri respecto de Aristóteles, comprobar la adecuación de la interpretación zubiriana de Aristóteles y la tercera y más importante, poner en claro los supuestos y las tesis de fondo que explican tanto las discrepancias como las coincidencias de ambos pensadores.

No parece caber duda de que algunos de los textos aristotélicos fundamentales que hemos citado en la primera parte de este trabajo han sido meditados en profundidad por Zubiri y están en la base, nos parece, de sus tesis acerca de la verdad real. Los esfuerzos de Zubiri por establecer distancias entre lo que él dice y lo afirmado por Aristóteles no deben impedir que constatemos algunos temas capitales en Zubiri a los que se puede encontrar su antecedente en Aristóteles. Lo dicho no significa que dejemos de pensar que con los mismos ladrillos, vigas, y cementos se pueden construir casas muy dispares entre sí. Seguramente éste es, en parte, el caso entre Aristóteles y Zubiri en el tema que examinamos. Nuestro intento será sólo señalar justamente esos materiales que Zubiri recuperó de Aristóteles para construir su propio edificio filosófico. 
Nos parece que algunas líneas maestras trazadas por Aristóteles en la concepción de la verdad han sido adoptadas y adaptadas por Zubiri. Especialmente la idea de que no hay solo un tipo de verdad, sino que básicamente cabe distinguir entre una verdad que es la que aparece en los juicios y otra verdad anterior en el sentido de ser fundamento y raíz de la posibilidad de verdad y error en dichos juicios (verdad antepredicativa en Aristóteles). Zubiri, como sabemos, distingue básicamente entre verdad real (simple) y verdad dual, modalizada en verdad como autenticidad, conformidad o cumplimiento (Inteligencia y realidad, 235). Precisamente en esta página se señala que: "toda verdad dual se halla fundada en verdad real".

También la tesis de que en la aprehensión de esa verdad fundante no cabe error posible, por lo que el tipo de aprehensión intelectiva implicada en dicha verdad fundante (aprehensión primordial de realidad en su modalización primaria y radical) ha de ser una modalización diferente de la que sí ofrece la posibilidad de verdad y error (modalidades ulteriores de la aprehensión primordial en el logos y la razón).

Estas serían, a nuestro juicio, tres tesis aristotélicas básicas que podemos encontrar en Zubiri (que existen básicamente dos tipos de verdades, que una es el fundamento de la otra y que en la verdad fundante no cabe error). Examinaremos a continuación otras afirmaciones aristotélicas que han encontrado eco en Zubiri y que precisan más matizaciones.

En primer lugar revisaremos las características fundamentales de la aprehensión primordial de realidad en su modalización primaria y radical. Se trata, según Zubiri, de aprehensión directa, inmediata y unitaria. Comparémoslas con las características que atribuye Aristóteles al acto de intelección (voṽ $)$ de los indivisibles.

Respecto de la primera característica (directa) habría discrepancia en tanto que Aristóteles señala en De an. III, 7, 431a 16-17 que "el alma jamás intelige sin el concurso de una imagen", mientras Zubiri asevera que la aprehensión primordial de realidad se realiza sin el concurso de imágenes o representaciones (Inteligencia y realidad, 67. 257). Una de las claves de esta discrepancia se encuentra en que la gnoseología aristotélica supone una íntima colaboración entre sensibilidad, imaginación e intelecto, de modo tal que "el intelecto intelige las formas en las imágenes" (De an. III, 7, 431b 2). Nos encontramos en las fuentes de la denuncia zubiriana del dualismo "sentir-inteligir". En el citado dualismo se requiere una facultad que haga de intermediaria entre sensibilidad e intelecto. Y dicha facultad es la imaginación. De ahí la citada afirmación aristotélica. 
Sobre este asunto, como clave de la distancia entre Aristóteles y Zubiri, volveremos al final de estas páginas ${ }^{69}$.

La segunda característica de la aprehensión primordial de realidad es ser inmediata. Así hemos caracterizado también la aprehensión de los indivisibles en Aristóteles. Pero varias y graves son las discrepancias sobre este asunto. En primer lugar, para Aristóteles la aprehensión de los indivisibles es la intelección de determinado tipo de contenidos mientras que para Zubiri toda intelección es aprehensión primordial de realidad. En segundo lugar para Aristóteles la intelección de los indivisibles no excluye un proceso de indagación previa ${ }^{70}$, en cambio para Zubiri por la intelección estamos ya en la realidad y, en consecuencia, en la verdad real. En tercer lugar, hemos tratado de mostrar que Aristóteles concibe dicho acto de intelección de los indivisibles como una "intuición" (võ̃s). Las mismas palabras de Zubiri pueden marcar aquí claramente las discrepancias:

“[S]i se toma la aprehensión primordial como mero acto de conciencia, se pensaría que la aprehensión primordial de realidad es la conciencia inmediata y directa de algo, intuición. Pero esto es imposible. Como vimos en el primer capítulo, se trata de aprehensión y no de mera conciencia. La impresión, como ya dije, no es en primera línea unidad noético-noemática de conciencia, sino que es un acto de aprehensión, una noergia, un érgon"71.

Reparemos ahora en la tercera característica, la unitariedad que implica simplicidad. Zubiri señala que:

"Para Aristóteles ser simple consiste en no tener multiplicidad ninguna, en ser 'sencillo' por así decirlo; así las cualidades sensibles como objeto formal propio de cada sentido serían ta haplá. Lo aprendido en intelección sentiente tiene en general una gran variedad de notas, es un sistema sustantivo de notas.

69 Al margen de que el dualismo extremo "sentir-inteligir" sea insostenible, la pregunta que queda en el aire, respecto de Zubiri, es si podemos concebir una intelección al margen de toda imagen mental, entendida en sentido amplio.

70 Tal y como se dice al final de Top. I, 2: “ En efecto, a partir de los principios propios de la ciencia en cuestión, es imposible decir nada sobre ellos mismos, puesto que los principios son primeros con respecto a todas las cosas, y por ello es necesario discurrir en torno a ellos a través de las cosas plausibles concernientes a cada uno de ellos. Ahora bien, esto es propio o le pertenece principalmente a la dialéctica: en efecto, al ser adecuada para examinar $<$ cualquier cosa $>$, abre camino a los principios de todas las disciplinas": Aristóteles, Tratados de lógica (Órganon) I: Categorías, Tópicos, Sobre las refutaciones sofisticas, trad. Miguel Candel Sanmartín (Madrid: Gredos, 1982). Pensamos que esa indagación previa de que hablamos es una búsqueda dialéctica que "abre camino a los principios", pero no los alcanza. Ésta es la tarea del voũc.

71 Zubiri, Inteligencia sentiente. *Inteligencia y realidad, 67. Ciertamente el apunte crítico va primaria y directamente contra la fenomenología de raíz husserliana. 
La simplicidad de esta aprehensión no consiste, pues, en la "sencillez" de lo aprehendido sino en que toda su interna variedad está aprehendida en y por sí misma de una manera unitaria. No se trata, pues, de la sencillez de un contenido (la cual en definitiva nunca se da), sino de la simplicidad del modo de aprehensión, a saber, el modo de aprehender algo directamente, inmediatamente y unitariamente, es decir, per modum unius ${ }^{, 72}$.

Nos atrevemos a decir que, después de lo explicado acerca de la intelección de los indivisibles, esta crítica de Zubiri hacia Aristóteles no rige en cierto sentido. Ya vimos, explicando De an. III, 6, que se habla de indivisibles, pero se matiza diferenciando realidades que son indivisibles en potencia y en acto de aquellas que son actualmente indivisibles, pero que potencialmente son divisibles. Ya explicamos cómo esta divisibilidad potencial implicaba o podía implicar precisamente complejidad. Los ejemplos y lo dicho por Zubiri a continuación no es incompatible con lo sostenido por Aristóteles:

"Ver un paisaje, ver un libro, en bloque, por así decirlo, sin pararse a aprehender cada una de sus notas o conjuntos parciales de ellas, es una aprehensión simple en el sentido de unitaria. Esta visión unitaria del sistema, ratificada en la intelección de lo así presentado es su verdad real simple" ${ }^{\text {73. }}$.

Sin embargo, hay que reconocer que la crítica zubiriana sí rige en otro sentido. En De an. III, 6 la indivisión, que es lo que da unidad a la realidad inteligida, es un carácter meramente negativo y consecutivo a la unidad misma: no es lo que formalmente constituye la unidad de modo positivo. De ahí quw la crítica de Zubiri a Aristóteles sea acertada en este punto: "La realidad sustantiva es indivisa porque es una, y no al revés" $" 74$.

Y es que mientras que la intelección de los indivisibles recae sobre cierto tipo de realidades, la aprehensión primordial de realidad es la raíz de toda aprehensión de la inteligencia sentiente. Los indivisibles aprehendidos entrarán a formar parte de "combinaciones" producidas por el intelecto para emitir juicios. En cambio, en Zubiri, lo aprehendido en impresión primordial de realidad es verdad real que deberá ser desplegada por el $\log _{0 s^{75}}$. En Aristóteles

72 Ibidem 237.

73 Ibidem 237; cf. 257.

74 Zubiri, Sobre la esencia, 286.

75 Cf. Ibidem 123. Zubiri, Inteligencia sentiente. *Inteligencia y realidad, 232-36. Xavier Zubiri, El hombre y Dios (Madrid: Alianza Editorial, 1986), 247-49. Zubiri no explica, al menos no claramente, cómo la verdad real es fundamento de la verdad dual: cf. Pintor-Ramos, Nudos en la filosofía de Zubiri, 230-31. Aristóteles sí parece hacerlo más claramente (el intelecto discursivo combina predicativamente noemas inteligidos con verdad antepredicativa), aunque tal vez no convincentemente. 
tendríamos, por así decir, aprehensiones "cerradas" que serán materiales para la inteligencia discursiva. En Zubiri, la aprehensión primordial de realidad está "abierta" a la indagación del logos para averiguar qué sea algo "en realidad" en una intelección campal que implica la presencia de una realidad "entre otras".

No podemos dejar de reseñar que mientras Aristóteles admite una enunciación de lo aprehendido en la percepción de los sensibles propios o en la intelección de los indivisibles (apartado 1.2.2), Zubiri no contempla ni siquiera una mera enunciación en lo aprehendido en la verdad real (apartado 2.3).

Tal vez una de las diferencias claves entre las dos doctrinas que analizamos está en que la verdad antepredicativa en Aristóteles lo es de determinadas realidades (sensibles propios y las realidades analizadas en el apartado 1.2.1). Dichas realidades entran luego en combinación por medio del intelecto en proposiciones de las que ya hay verdad en sentido estricto. Hay diferencia entre la percepción sensible que capta los sensibles propios, entre la intelección (voũ $\varsigma$ ) que capta los indivisibles (o las realidades carentes de composición) y los juicios posteriores del intelecto que combina dichas aprehensiones. Además, existen realidades para las que no hay intelección como indivisibles (acciones e individuos: ver apartado 1.2.2). A todo ello subyace en Aristóteles un dualismo entre sentir e inteligir subrayado en varias ocasiones por Zubiri ${ }^{76}$. Es más: esta concepción aristotélica es fruto, en gran medida, de dicho dualismo. Eliminado de raíz dicho dualismo en Zubiri, el panorama que nos encontramos es completamente diferente. En Zubiri la aprehensión primordial de realidad no es un acto psíquico diferenciable, sino que es "una modalidad elemental que subyace a todo acto intelectivo, cualquiera que éste sea en concreto" "77. Ya no hay una labor posterior del logos de "combinar" lo aprehendido, sino que hay una labor de despliegue de lo ya inteligido en y por sí mismo para saber lo que es "en realidad". Como vimos, en Aristóteles podía haber una cierta labor de búsqueda previa para llegar a la verdad antepredicativa. En Zubiri la indagación es propia del logos y, por tanto, no hay que "llegar a la realidad" por medio de los sentidos o la indagación (Aristóteles), sino que ya se está en la realidad desde el principio, desde la aprehensión primordial de realidad (Zubiri ${ }^{78}$ ). La superación de este

76 En las siguientes páginas referido explícitamente a Aristóteles: Zubiri, Inteligencia sentiente. *Inteligencia y realidad, 80. 128. Ver también, por ejemplo, las páginas 11-13. 247; Zubiri, Sobre la esencia, 417-18.

77 Pintor-Ramos, Nudos en la filosofía de Zubiri, 214-15. Idea expresada muy claramente, por ejemplo, en Zubiri, Inteligencia sentiente. *Inteligencia y realidad, 247.

78 "El hombre se encuentra no solamente atenido a la realidad, sino además henchido de realidad. Quiéralo o no lo quiera, por muy nihilista que se declare, el hombre vive henchido de realidad. En todos los actos que ejecuta a lo largo de su vida, en todas las dimensiones de estos actos -por muy 
dualismo en Zubiri le permite discrepar de Aristóteles también en un punto capital: para éste, la verdad es cosa de la inteligencia; para Zubiri, la verdad radical que es la verdad real, aún siendo en la inteligencia es formal y radicalmente de la cosa misma ${ }^{79}$.

\section{REFERENCIAS BIBLIOGRÁFICAS}

Aristote. De l'âme. Traducción y notas por E. Jannone, A. Barbotin. Paris: Les Belles Lettres, 1996.

Aristóteles. Acerca del alma. Traducción y notas por Tomás Calvo Martínez. Madrid: Gredos, 1988.

—. Ética a Nicómaco. Traducción y notas por María Araujo y Julián Marías. Madrid: Centro de Estudios Políticos y Constitucionales, 1989.

- Metafísica. Traducción y notas por Valentín García Yebra. Madrid: Gredos, 1987.

- Metafísica. Traducción y notas por Tomás Calvo Martínez. Madrid: Gredos, 1994.

—. Tratados de lógica (Órganon) I: Categorías, Tópicos, Sobre las refutaciones sofisticas. Traducción y notas por Miguel Candel Sanmartín. Madrid: Gredos, 1982.

- Tratados de lógica (Órganon) II: Sobre la interpretación, Analíticos primeros, Analíticos segundos. Traducción y notas por Miguel Candel Sanmartín. Madrid: Gredos, 1988.

Aristotle. Metaphysics. Editado por W. David Ross. Oxford: Clarendon Press, 1924.

- Parva naturalia. Editado por W. David Ross. Oxford: Oxford University Press, 1970.

Berti, Enrico. " 'Indivisibles' according to Aristotle, De anima III 6". En Aristotle on Mind and the Senses. Proceedings of the Seventh Symposium Aristotelicum, editado por G.E.L Lloyd, Geoffrey E.R.; Owen, 141-63. London-New York: Cambridge University Press, 1978.

Besoli, Stefano. "Percezione, verità e giudizio: Luoghi dell'intuizionismo aristotelico". Annali dell'Instituto discipline filosofiche dell'Università di Bologna 4 (1982): 5-40.

Bravo García, Antonio. "Fisiología y filosofía en Aristóteles: el problema de los sueños". Cuadernos de Filología (C. Univ. de Ciudad Real) 4 (1985): 15-

poco intelectuales que sean- va siempre envuelto un momento de realidad, que es lo que da al acto humano su carácter específicamente humano": Zubiri, El hombre y la verdad, 38.

79 Cf. Zubiri, Inteligencia sentiente. *Inteligencia y realidad, 34; El hombre y Dios, 214. 
65.

Burnet, John. The Ethics of Aristotle. London: Methuen and Co., 1900.

Conderana Cerrillo, Jesús Manuel. El conocimiento de los principios prácticos en Aristóteles. Salamanca: Publicaciones de la Universidad Pontificia de Salamanca, 2002.

Durán Martínez, Inés. "El nous en Aristóteles: análisis léxico del término". Tesis doctoral, Universidad Complutense de Madrid, 2002.

Kahn, C. H. "The Role of nous in the Cognition of First Principles". En Aristotle on Sience. The Posterior Analytics, editado por Enrico Berti, 385-414. Editrice Antenore, 1981.

Modrak, Deborah K. W. Aristotle. The Power of Perception. Chicago-London: University of Chicago Press, 1987.

Moreau, Joseph. "Aristote et la vérité antépredicative". En Aristote et les problémes de méthode (Communications présentées au Symposium Aristotelicum tenu à Louvain du 24 août au ler septembre 1960, editado por Suzanne Mansion, 21-33. Louvain-Paris: Publications Universitaires de Louvain-Éditions Béatrice-Neuwelaerts, 1980.

Palacios, Juan Miguel. "Vida moral y saber moral". En El deber gozoso de filosofar: homenaje a Miguel García-Baró, editado por A. Serrano de Haro, 363-75. Salamanca: Sígueme, 2018.

Pintor-Ramos, Antonio. Nudos en la filosofía de Zubiri. Salamanca: Publicaciones de la Universidad Pontificia de Salamanca, 2006.

Sancti Thomae Aquinatis. Summa Theologiae (texto latino de la edición critica Leonina y traducción castellana). Madrid: Biblioteca de Autores Cristianos, 1954.

Zubiri, Xavier. El hombre y Dios. Madrid: Alianza Editorial, 1986.

-. El hombre y la verdad. Madrid: Alianza Editorial, 1999.

-. Inteligencia sentiente. *Inteligencia y realidad. Madrid: Alianza Editorial, 1980.

—. Inteligencia y logos. Madrid: Alianza Editorial, 1982.

—. Sobre la esencia. 4. ${ }^{a}$ ed. Madrid: Sociedad de Estudios y Publicaciones, 1962.

Jesús Manuel Conderana Cerrillo Facultad de Filosofía Universidad Pontificia de Salamanca Calle Compañía 5 37002 Salamanca (España) jmconderanace@upsa.es http://orcid.org/0000-0002-4699-0463 